\title{
Structure and Chemical Transformation in Cerium Oxide Nanoparticles Coated by Surfactant Cetyltrimethylammonium Bromide (CTAB): An X-ray Absorption Spectroscopic Study
}

\author{
Zhonghua Wu, $, \dagger, \downarrow$ Jing Zhang, ${ }^{\dagger}$ Robert E. Benfield, ${ }^{\ddagger}$ Yongfan Ding, ${ }^{\dagger}$ Didier Grandjean, $;$ \\ Zhaoli Zhang, ${ }^{\S}$ and Xin Ju ${ }^{\dagger}$ \\ BSRF, Institute of High Energy Physics, Chinese Academy of Sciences, P.O. Box 918, Bin 2-7, \\ Beijing 100039, P. R. China, Centre for Materials Research, School of Physical Sciences, University of Kent, \\ Canterbury, CT2 7NR, U.K., and Beijing Laboratory of Electron Microscopy, Institute of Physics \& Centre for \\ Condensed Matter of Physics, Chinese Academy of Sciences, Beijing 100080, P. R. China
}

Received: April 23, 2001; In Final Form: January 17, 2002

\begin{abstract}
Cerium oxide nanoparticles coated by cetyltrimethylammonium bromide (CTAB) were prepared using reverse micelles and microemulsion method. The as-prepared nanoparticles $\left(25^{\circ} \mathrm{C}\right)$ were annealed at $200,350,500$, and $700{ }^{\circ} \mathrm{C}$ for $2 \mathrm{~h}$. Their particle sizes are, respectively, 230, 50,2, 6, and $10 \mathrm{~nm}$ as identified by transmission electron microscopy and $\mathrm{X}$-ray diffraction patterns. A chemical transformation from amorphous $\mathrm{Ce}^{3+}$ component to crystalline $\mathrm{Ce}^{4+}$ component was found in the temperature range of $200{ }^{\circ} \mathrm{C}$ to $400{ }^{\circ} \mathrm{C}$. X-ray absorption spectroscopy was used to reveal the electronic and atomic structures. The intermediate spectroscopic valence of formally tetravalent compounds and four features A, B, C, and D were detected from the X-ray absorption near edge structure (XANES) spectra of Ce- $\mathrm{L}_{\mathrm{III}}$ absorption for samples annealing at 350,500 , and $700{ }^{\circ} \mathrm{C}$. As in trivalent bulk $\mathrm{Ce}\left(\mathrm{NO}_{3}\right)_{3} \cdot 6 \mathrm{H}_{2} \mathrm{O}$, the $\mathrm{Ce}^{3+}$ characteristic was also found for samples annealing at 25,200 , and $350^{\circ} \mathrm{C}$. Multielectron excitation effect on the EXAFS spectra was eliminated. Local atomic structures of these nanoparticles were probed by using extended X-ray absorption fine structure (EXAFS) technique. The obtained structural parameters for bulk $\mathrm{Ce}\left(\mathrm{NO}_{3}\right)_{3} \cdot 6 \mathrm{H}_{2} \mathrm{O}$ were in excellent agreement with its crystallographic data. For nanoparticles annealed at $500{ }^{\circ} \mathrm{C}$ and $700{ }^{\circ} \mathrm{C}$, similar atomic structures with bulk $\mathrm{CeO}_{2}$ were found. For the as-prepared nanoparticles without annealing $\left(25^{\circ} \mathrm{C}\right)$, a single shell $(10 \times 2.59 \AA)$ is sufficient to describe its local structures, while two shells had to be used for the nanoparticles annealed at $200{ }^{\circ} \mathrm{C}$ and 350 ${ }^{\circ} \mathrm{C}$. One shell is corresponding to the $\mathrm{Ce}^{3+}$ component. Another is corresponding to the $\mathrm{Ce}^{4+}$ component. All $\mathrm{Ce}^{4+}$ components have the same structural parameters except different Debye-Waller factors or atom-pair distribution functions. A core-shell model was used to explain the structural parameters around cerium for the two samples annealed at $200{ }^{\circ} \mathrm{C}$ and $350{ }^{\circ} \mathrm{C}$. The core part is the $\mathrm{Ce}^{4+}$ component with crystalline $\mathrm{CaF}_{2^{-}}$ type cubic structures (eight oxygens at $2.343 \AA$ around $\mathrm{Ce}$ ); the shell part is an amorphous $\mathrm{Ce}^{3+}$ component with different structures. The mechanism of chemical transformation was discussed in this paper.
\end{abstract}

\section{Introduction}

Rare earth compounds have wide applications because of their special electronic configuration. However, nanostructural rare earth compounds, because of the high surface-to-volume ratio and quantum-size effect, ${ }^{1,2}$ present unusual chemical and physical properties different from those of bulk materials. The potential properties and applications of nanometer-scaled cerium compounds prompt a wide research from synthesis, structures, and properties to applications. Recently, there has been a great scientific interest ${ }^{3-12}$ in the synthesis of $\mathrm{CeO}_{2}$ nanoparticles and the modifications of their size, morphology, and property for a

* To whom correspondence should be addressed. E-mail: wuzh@ mail.ihep.ac.cn.

Institute of High Energy Physics.

$\doteqdot$ University of Kent.

$\S$ Institute of Physics \& Centre for Condensed Matter of Physics. large variety of applications such as ultraviolet absorbent, glasspolishing materials, and three-way catalysts for the automotive industry.

X-ray absorption spectroscopy technique has been frequently used to probe the electronic and atomic structures of materials. For compounds with $\mathrm{Ce}^{4+}$ oxidation state, the origin of the two main peaks on the X-ray absorption spectrum has been also disputed for a long time. The covalent mixing ${ }^{13-16}$ of $4 \mathrm{f}$ states and multielectron resonance ${ }^{17-21}$ at the $\mathrm{Ce}-\mathrm{L}_{\mathrm{III}}$ edge makes the X-ray absorption spectroscopy more complicated. X-ray absorption spectroscopy of Ce- $\mathrm{L}_{\text {III }}$ edge contains the information of electron structures such as the final-state mixed-valence behavior, the intense multielectron excitations, and the chemical valence states. Some spectroscopic features are tightly connected with atomic and electronic structures. At the same time, they also bring difficulties in the X-ray absorption data analysis. 


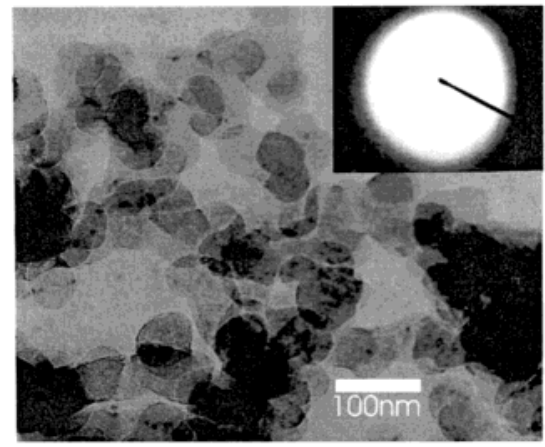

Figure 1. Transmission electron micrograph of CTAB-coated cerium oxide nanoparticles annealed at $200{ }^{\circ} \mathrm{C}$ for $2 \mathrm{~h}$. TEM diffraction pattern shown in the inset image demonstrates that these nanoparticles are in an amorphous form.

Studying the X-ray absorption spectroscopy of Ce- $\mathrm{L}_{\mathrm{III}}$ edge is very important in both theory and practice.

Recently, many theoretical and experimental researches have been reported on the final-state mixed-valence behavior and the intense multielectron excitations of cerium oxides and compounds at the $\mathrm{L}_{\mathrm{III}}$ edge of cerium. However, few reports ${ }^{18,22}$ can be found on their extended X-ray absorption-fine-structure (EXAFS) studies, especially for nanometer-scaled cerium oxides coated by surfactants. We are interested in the effect of surfactants on the nanoparticles. To utilize better nanometerscaled materials, studying their structures and stability is very important. The synthesis of the nanoscaled cerium oxide nanoparticles coated by surfactant cetyltrimethylammonium bromide (CTAB) promotes us to examine and compare their local atomic structures and the X-ray absorption spectroscopic features with the bulk counterpart. The structural dependence on temperature and chemical transformation were investigated by using EXAFS and X-ray absorption near edge structure (XANES) techniques in this paper.

\section{Experimental Section}

2.1 Sample Preparation. Monodispersive cerium oxide nanoparticles were prepared in "microreactors" of reverse micelles and microemulsions, formed from cetyltrimethylammonium bromide, butanol, and $\mathrm{Ce}\left(\mathrm{NO}_{3}\right)_{3} \cdot 6 \mathrm{H}_{2} \mathrm{O}$ in cyclohexane. The synthesis process is as follows: (1) $5 \mathrm{~g}$ cetyltrimethylammonium bromide $\left(\mathrm{C}_{16} \mathrm{H}_{33}-\left(\mathrm{CH}_{3}\right)_{3}-\mathrm{N}^{+} \mathrm{Br}^{-}, \mathrm{CTAB}\right)$ and $2 \mathrm{~mL}$ of $0.5 \mathrm{M}$ aqueous $\mathrm{Ce}\left(\mathrm{NO}_{3}\right)_{3} \cdot 6 \mathrm{H}_{2} \mathrm{O}$ were added into $200 \mathrm{~mL}$ cyclohexane. After that, an appropriate amount of butanol was stirred into the mixture until the transparent microemulsion was formed. (2) $5 \mathrm{~g}$ cetyltrimethylammonium bromide and $2 \mathrm{~mL}$ ammonia were added into $200 \mathrm{~mL}$ cyclohexance. Then, an appropriate amount of butanol was stirred into the mixture until the transparent microemulsion was formed. (3) The two microemulsions were mixed and stirred for $1 \mathrm{~h}$. The resultant mixture turns into a colloid solution with opalescence. The powder of cerium oxide nanoparticles was obtained from this colloid solution by rotatory evaporation. The as-prepared sample (at $25^{\circ} \mathrm{C}$ ) was further annealed, respectively, at 200, 350, 500, and $700{ }^{\circ} \mathrm{C}$ for $2 \mathrm{~h}$ under air condition. The resulting samples were, respectively, labeled as Ce25, Ce200, Ce350, Ce500, and Ce700.

2.2 TEM and XRD Characterization. The cerium oxide nanoparticles were characterized using transmission electron microscopy (TEM, JEM 200-CX) with an accelerating voltage of $100 \mathrm{kV}$. Figure 1 shows the TEM photograph of the sample $\mathrm{Ce} 200$ with particle size of $50 \mathrm{~nm}$. Figure 2 is the high-resolution

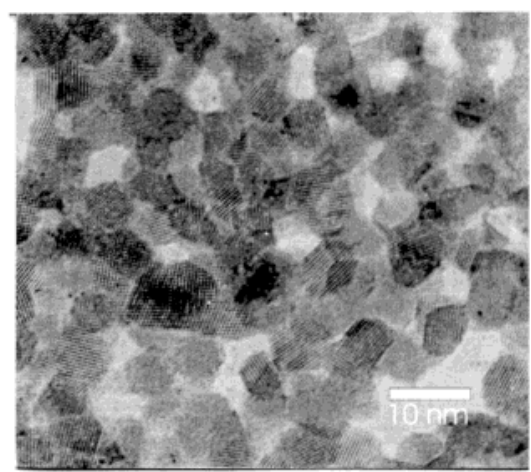

Figure 2. High-resolution transmission electron micrograph of CTABcoated cerium oxide nanoparticles annealed at $500{ }^{\circ} \mathrm{C}$ for $2 \mathrm{~h}$. The clear stripes in the image illustrate the nanoparticles are in a crystalline form.

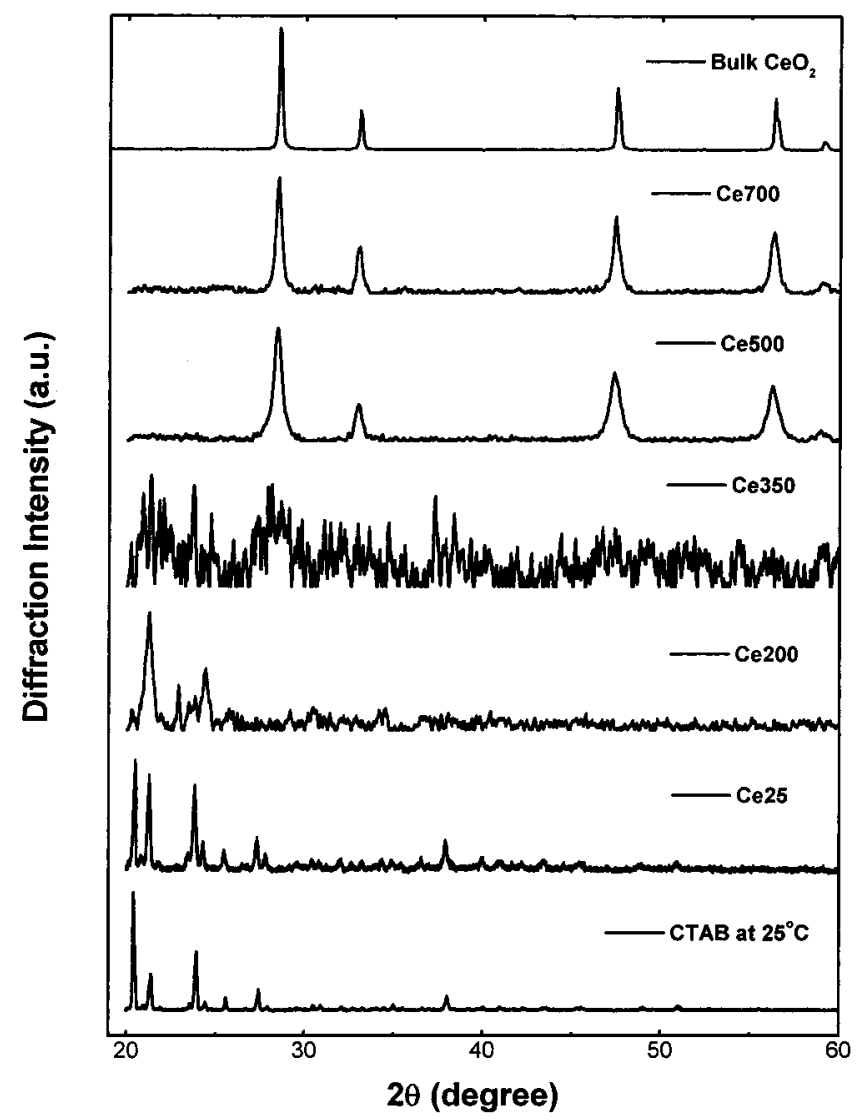

Figure 3. X-ray diffraction patterns of bulk $\mathrm{CeO}_{2}$ (the upper), pure surfactant CTAB (the lower), and CTAB-coated cerium oxide nanoparticles (the middle) annealed at different temperatures (from bottom to top, $25,200,350,500$, and $700{ }^{\circ} \mathrm{C}$ ) for $2 \mathrm{~h}$.

TEM photograph of sample Ce500 with particle size of $6 \mathrm{~nm}$. Figure 3 shows the X-ray diffraction (XRD) patterns of bulk $\mathrm{CeO}_{2}$ and cerium oxide nanoparticles, which were recorded on a Rigaku RINT/Dmax-2000 diffractometer using $\mathrm{Cu}-\mathrm{K} \alpha$ radiation $(\lambda=1.5406 \AA$ ). Obviously, samples annealed above 500 ${ }^{\circ} \mathrm{C}$ have the same crystalline structures as bulk $\mathrm{CeO}_{2}$. Their diffraction peaks corresponds one to one and can be roughly indexed as (111), (200), (220), and (311) allowing reflecting planes expected from cubic fluorite structure $\mathrm{CeO}_{2}$. However, for those nanoparticles annealed below $300{ }^{\circ} \mathrm{C}$, their XRD patterns are very similar to that of the pure surfactants (CTAB). We attribute these reflections to the contribution from survival of the surfactants (CTAB). No detectable diffraction peaks come from cerium oxide nanoparticles which means those nanopar- 


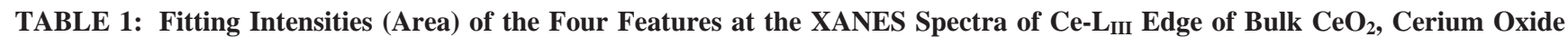
Nanoparticles, ${ }^{a}$ and Bulk $\mathrm{Ce}\left(\mathrm{NO}_{3}\right)_{3} \cdot 6 \mathrm{H}_{2} \mathrm{O}$

\begin{tabular}{|c|c|c|c|c|c|c|}
\hline samples & particle size $(\mathrm{nm})$ & $\mathrm{A}(12.7 \mathrm{eV})$ & $\mathrm{B}(5.8 \mathrm{eV})$ & $\mathrm{C}(1.6 \mathrm{eV})$ & $\mathrm{D}(-5.1 \mathrm{eV})$ & $v_{\mathrm{s}}=3+I_{\mathrm{A}} /\left(I_{\mathrm{A}}+I_{\mathrm{B}}\right)$ \\
\hline $\mathrm{Ce}\left(\mathrm{NO}_{3) 3} \cdot 6 \mathrm{H}_{2} \mathrm{O}\right.$ & & & & 18.18 & & \\
\hline $\mathrm{Ce} 25$ & $100.0 \pm 10.0$ & & & 21.58 & & \\
\hline $\mathrm{Ce} 200$ & $50.0 \pm 10.0$ & & & 20.02 & & \\
\hline CE350 & $2.0 \pm 0.5$ & 4.54 & 3.79 & 6.56 & 0.25 & 3.54 \\
\hline $\mathrm{Ce} 500$ & $6.0 \pm 0.8$ & 6.67 & 6.64 & 6.06 & 0.03 & 3.50 \\
\hline $\mathrm{Ce} 700$ & $10.0 \pm 1.0$ & 6.57 & 6.16 & 3.09 & 0.26 & 3.52 \\
\hline bulk $\mathrm{CeO}_{2}$ & & 6.08 & 5.93 & 3.63 & 0.13 & 3.51 \\
\hline
\end{tabular}

${ }^{a}$ Annealed, respectively, at $25,200,350,500$, and $700{ }^{\circ} \mathrm{C}$.

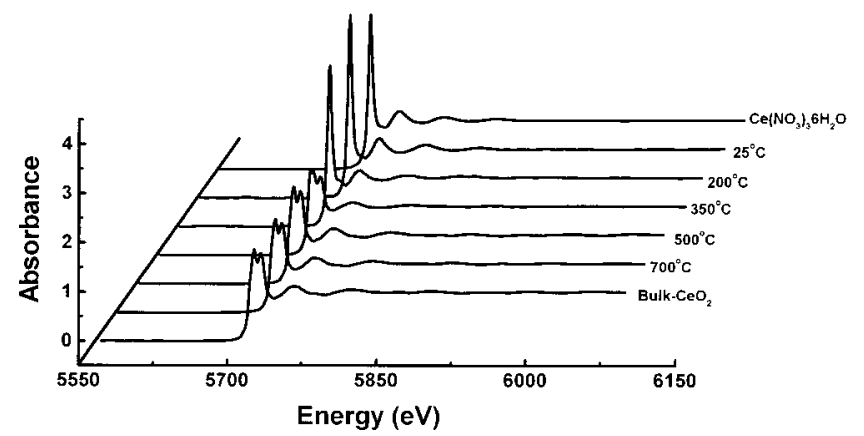

Figure 4. Normalized absorption curves of $\mathrm{L}_{\text {III }}$ edge in bulk $\mathrm{Ce}\left(\mathrm{NO}_{3}\right)_{3}$. $6 \mathrm{H}_{2} \mathrm{O}$, cerium oxide nanoparticles (annealed, respectively, at 25, 200, 350,500 , and $700{ }^{\circ} \mathrm{C}$ for $2 \mathrm{~h}$ ), and bulk $\mathrm{CeO}_{2}$.

ticles are in an amorphous state without long-range order in their structures. This was confirmed again by the electron diffraction pattern for the sample Ce200 as shown in the inset of Figure 1. The broadened XRD peaks in nanoparticles reflect the decrease of particle size. The Scherrer formula ${ }^{23}$ can also be used to evaluate the particle size. On the basis of the TEM and XRD results, the cerium oxide nanoparticle sizes are given in Table 1.

2.3 XAFS Spectra Collection. X-ray absorption spectra were collected on the EXAFS station (Beam line 4W1B) of Beijing Synchrotron Radiation Facility (BSRF). The storage ring was run at $2.2 \mathrm{GeV}$ with the electron current about $80 \mathrm{~mA}$. The beam lifetime was about $12 \mathrm{~h}$. The cerium oxides nanoparticles were homogeneously smeared on Scotch adhesive tape. More than eight layers were folded to reach the optimum absorption thickness $(\Delta \mu d \approx 1.0, \Delta \mu$ is the absorption edge step, $d$ is the physical thickness of the sample). X-ray absorption spectra of $\mathrm{Ce}-\mathrm{L}_{\mathrm{III}}$ edge of CTAB-coated cerium oxide nanoparticles, bulk $\mathrm{Ce}\left(\mathrm{NO}_{3}\right)_{3} \cdot 6 \mathrm{H}_{2} \mathrm{O}$ and bulk $\mathrm{CeO}_{2}$, were collected at ambient temperature in transmission mode. Higher harmonics were eliminated by detuning the double crystal Si (111) monochromator. The incident and transmission X-ray intensities were, respectively, detected by ion chambers that were installed in front of and behind the sample. X-ray energy was calibrated by using the $\mathrm{Cr}-\mathrm{K}$ absorption edge $(5989 \mathrm{eV})$. Energy resolution $(\Delta \mathrm{E} /$ $\mathrm{E})$ is about $2 \times 10^{-4}$. The absorption spectra were collected from $200 \mathrm{eV}$ below the absorption threshold to over $500 \mathrm{eV}$ above the threshold until the $\mathrm{L}_{\mathrm{II}}$ absorption edge appeared. The normalized absorption curves are shown in Figure 4.

\section{XANES Spectroscopy}

Figure 5 shows the normalized Ce- $\mathrm{L}_{\mathrm{III}}$ XANES spectra of bulk $\mathrm{CeO}_{2}$, cerium oxide nanoparticles annealed at temperature $25,200,350,500$, and $700{ }^{\circ} \mathrm{C}$, and bulk hydrous-cerium-nitrate $\left(\mathrm{Ce}\left(\mathrm{NO}_{3}\right)_{3} \cdot 6 \mathrm{H}_{2} \mathrm{O}\right)$. The energy, corresponding to the maximum of the first derivative of the absorption edge, was chosen as the energy threshold. As the same with bulk $\mathrm{CeO}_{2}$, four obvious features could be found from the XANES spectra of the samples

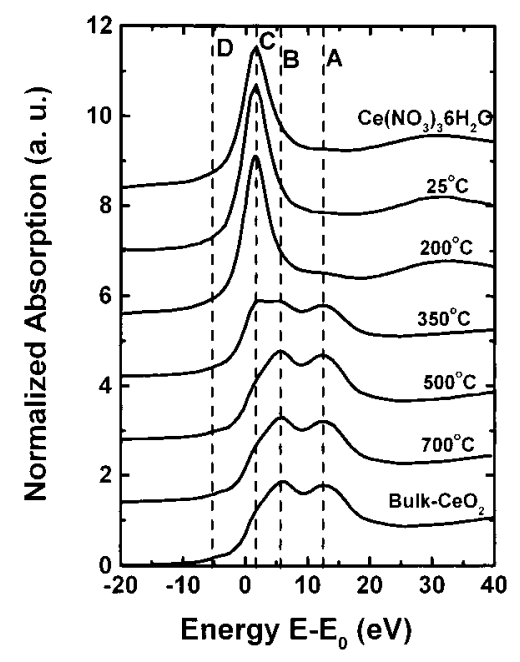

Figure 5. X-ray near-edge absorption spectra of bulk $\mathrm{CeO}_{2}$, cerium oxide nanoparticles (annealed, respectively, at 700, 500, 350, 200, and $25^{\circ} \mathrm{C}$ for $2 \mathrm{~h}$ ), and hydrous cerium nitrate (bulk $\mathrm{Ce}\left(\mathrm{NO}_{3}\right)_{3} \cdot 6 \mathrm{H}_{2} \mathrm{O}$ ) (from bottom to top). Four features A, B, C, and D are guided by the vertical dash lines.

Ce350, Ce500, and Ce700, that is, the high-energy feature A, the main feature $\mathrm{B}$, the low-energy feature $\mathrm{C}$, and the preedge feature D. Features A and B were described as mixing of the multielectron configurations ${ }^{14} 4 \mathrm{f}^{0} \mathrm{~L}$ and $4 \mathrm{f}^{1} \mathrm{~L}$, where $\mathrm{L}$ denotes a ligand $(\mathrm{O} 2 \mathrm{p})$ hole. Feature A could be also separated into two subpeaks $A_{1}$ and $A_{2}$ corresponding to the crystal field split of the $4 \mathrm{f}^{0} \mathrm{~L}$ final state. ${ }^{22}$ The low-energy shoulder $\mathrm{C}$ was due to the crystal field splitting of $\mathrm{Ce} 5 \mathrm{~d}$ states for bulk $\mathrm{CeO}_{2}{ }^{14}$ or was assigned to a $\mathrm{Ce}^{3+}$ impurity. ${ }^{16,24}$ The preedge peak $\mathrm{D}$ was the result ${ }^{14}$ of the transition to the unoccupied $\mathrm{Ce} d$ states at the bottom of the $\mathrm{CeO}_{2}$ conduction band or a dipole-forbidden $2 \mathrm{p}_{3 / 2} \rightarrow 4 \mathrm{f}$ transition, ${ }^{22}$ which is a consequence of $5 \mathrm{~d}$ admixtures to the $4 \mathrm{f}$ state. The sample $\mathrm{Ce} 350$ has evidently higher intensity in feature C. The samples Ce25 and Ce200 show a drastic increase in the peak corresponding to feature $C$, while features $\mathrm{A}, \mathrm{B}$, and D have almost disappeared in the two samples. This spectral feature is very similar to the case of bulk hydrouscerium-nitrate $\left(\mathrm{Ce}\left(\mathrm{NO}_{3}\right)_{3} \cdot 6 \mathrm{H}_{2} \mathrm{O}\right)$ in which $\mathrm{Ce}$ has an unambiguous $\mathrm{Ce}^{3+}$ oxidation state. Before any data analysis, we can conclude that a chemical transformation occurs at an annealing temperature around $300{ }^{\circ} \mathrm{C}$.

Features $\mathrm{A}$ and $\mathrm{B}$ are characteristic of $\mathrm{Ce}^{4+}$ oxides and compounds. $\mathrm{Ce}^{3+}$ compounds, for example, $\mathrm{CeF}_{3}{ }^{25}$ and $\mathrm{Ce}$ $\left(\mathrm{NO}_{3}\right)_{3} \cdot 6 \mathrm{H}_{2} \mathrm{O}$ herein, have obviously different spectral features. The main peak of $\mathrm{Ce}\left(\mathrm{NO}_{3}\right)_{3} \cdot 6 \mathrm{H}_{2} \mathrm{O}$ has a quite high intensity and coincides with the low-energy shoulder $\mathrm{C}$ of bulk $\mathrm{CeO}_{2}$. This spectral difference is an important judgment of distinguishing $\mathrm{Ce}^{3+}$ and $\mathrm{Ce}^{4+}$ compounds. For nanometer-scale metallic clusters, ab initio calculation ${ }^{26}$ demonstrates that the particle size is also a significant parameter on the XANES and can change the shape of XANES part. 


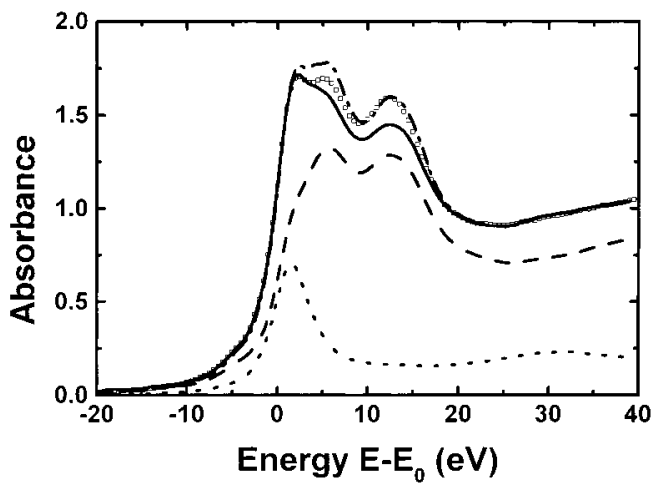

Figure 6. Experimental XANES spectrum (open square) and its

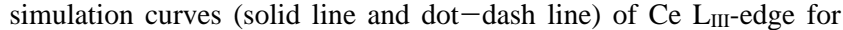
cerium oxides nanoparticles annealed at $350{ }^{\circ} \mathrm{C}$ for $2 \mathrm{~h}$. Clearly, the experimental XANES spectrum cannot be simulated well by combining the two components of bulk $\mathrm{CeO}_{2}$ (dash line) and nanoparticles without annealing (sample Ce25, dot line). Two cases, (1) $80 \%$ bulk $\mathrm{CeO}_{2}+$ $20 \% \mathrm{Ce} 25$ (dot-dash line) and (2) $79 \%$ bulk $\mathrm{CeO}_{2}+21 \% \mathrm{Ce} 25$ (solid line), are shown in the figure.

From Figure 5, it can be seen that samples Ce25, Ce200, and $\mathrm{Ce}\left(\mathrm{NO}_{3}\right)_{3} \cdot 6 \mathrm{H}_{2} \mathrm{O}$ have similar shapes and the same energy positions in the main peaks. In sample $\mathrm{Ce} 350$, although the $\mathrm{Ce}^{4+}$ features (peaks A and B) are dominant, a slightly higher peak $\mathrm{C}$ with consistent position implies that this sample presents partially the characteristic of $\mathrm{Ce}^{3+}$ component. With the annealing temperature increasing as in samples Ce500 and Ce700, the intensity of feature $\mathrm{C}$ decreases and closes to the level found in bulk $\mathrm{CeO}_{2}$. A quite weak feature $\mathrm{A}$ can be faintly seen from the XANES spectrum of sample Ce200. This possibly implies that a $\mathrm{Ce}^{4+}$ component begins to appear. From these spectral features, it can be roughly obtained that a chemical transformation from $\mathrm{Ce}^{3+}$ to $\mathrm{Ce}^{4+}$ took place, as the nanoparticles were annealed at temperatures from $200{ }^{\circ} \mathrm{C}$ to $400{ }^{\circ} \mathrm{C}$.

The main peak has more broadened width and lower height in $\mathrm{Ce}\left(\mathrm{NO}_{3}\right)_{3} \cdot 6 \mathrm{H}_{2} \mathrm{O}$ than in samples $\mathrm{Ce} 25$ and $\mathrm{Ce} 200$. This tells us that the atomic structures in the two kinds of nanoparticles are more ordered than in bulk $\mathrm{Ce}\left(\mathrm{NO}_{3}\right)_{3} \cdot 6 \mathrm{H}_{2} \mathrm{O}$. It can be attributed to the chemical inhomogeneity locally, that is, $\mathrm{Ce}$ has a more symmetric and narrow-distributional $\mathrm{Ce}-\mathrm{O}$ shell in nanostructures than in the starting material. Without a further heat treatment of sample Ce25, the surfactant CTAB coated on the nanoparticles should be quite intact and surpluses of surfactant should be retained in the sample. With the annealing temperature increasing to $200{ }^{\circ} \mathrm{C}$, the surfactant $\mathrm{CTAB}$ will be partially decomposed. This annealing not only destroys partially the surfactant, but also changes the structures and reduces the structural order of nanoparticles. This explains why sample $\mathrm{Ce} 200$ has a lower intensity of main peak than sample Ce25.

The XANES spectrum of sample Ce350 cannot be well simulated by the two components of bulk $\mathrm{CeO}_{2}$ and sample $\mathrm{Ce} 25$ as shown in Figure 6. It is between the two cases of $80 \%$ of $\mathrm{CeO}_{2}+20 \%$ of $\mathrm{Ce} 25$ and $19 \%$ of $\mathrm{CeO}_{2}+81 \%$ of $\mathrm{Ce} 25$. This demonstrates that the nanoparticles annealed at $350{ }^{\circ} \mathrm{C}$ are not the simple addition of the two samples. Bazin et al. ${ }^{26}$ also pointed out that for nanometer-scale materials, it is definitely not possible to simulate their XANES part for the K edge with a linear combination of the XANES of wellcrystallized reference compounds. Certainly, XANES features are tightly connected with electron and atomic structures. From this simulation, we believe that sample Ce 350 consists of two $\mathrm{Ce}^{3+}$ and $\mathrm{Ce}^{4+}$ components. The content of $\mathrm{Ce}^{4+}$ component approximates to $80 \%$ and that of $\mathrm{Ce}^{3+}$ component is close to $20 \%$.
Before XANES fitting, a linear preedge background was fitted and removed. The edge height was fitted and normalized to unity with an arctangent function. The postedge background was modified to the constant unity. The maximum of the first derivative of the edge region was chosen as the energy threshold. The XANES background can be, respectively, chosen as one arctan function, one sigmoidal function, two arctan functions (corresponding to the two electron configurations $4 \mathrm{f}^{0} \mathrm{~L}$ and $4 \mathrm{f}^{1} \mathrm{~L}$ ), or three arctan functions (corresponding to the $\mathrm{Ce}^{3+}$ and the electron configurations of $\mathrm{Ce}^{4+}$ ) and so on. The total absorption jump can be fixed at one or fitted as a fitting parameter. Gaussian, Lorentzian, and Gaussian broadened Lorentzian functions ${ }^{27,28}$ can, respectively, be chosen as the shape function of the XANES features. Therefore, different fitting models can be chosen to fit the XANES features. We also noticed that the fitting parameters for different models could be slightly different. The spectroscopical valence for $\mathrm{Ce}_{2} \mathrm{Fe}_{16.8}$ was reported ${ }^{28}$ to change from 3.54 to 3.64 for four different fitting models. However, the XANES features and their fitting parameters can be compared to each other by using the same fitting model in a studied system. In our case, we have $\mathrm{Ce}^{3+}$ samples, $\mathrm{Ce}^{4+}$ samples, and the mixtures of $\mathrm{Ce}^{3+}$ and $\mathrm{Ce}^{4+}$ components. For comparison between different samples, we chose one arctan function to fit the absorption step edge and left the step height as a fitting parameter. Four Gaussian broadened Lorentzian functions were used to fit the XANES features. The positions of features A, B, C, and D were, respectively, fixed at 12.7, $5.8,1.6$, and $-5.1 \mathrm{eV}$, corresponding to the maximum of these features. The fitting areas (intensity) of the four features are listed in Table 1.

The XANES spectra of samples $\mathrm{Ce} 25, \mathrm{Ce} 200$, and $\mathrm{Ce}\left(\mathrm{NO}_{3}\right)_{3}$. $6 \mathrm{H}_{2} \mathrm{O}$ were fitted only with an arctan function and a Gaussian broadened Lorentzian function. The four features were also tried in the fitting of $\mathrm{Ce} 200$, but the intensities of features A, B, and $\mathrm{D}$ are quite weak. They are not given in Table 1. Features A and $\mathrm{B}$ correspond to the transitions to the $5 \mathrm{~d}$ states of cerium with $4 \mathrm{f}^{0}$ and $4 \mathrm{f}^{1}$ valence configurations. $I_{\mathrm{A}}$ and $I_{\mathrm{B}}$ were, respectively, used to label the intensities of features $\mathrm{A}$ and $\mathrm{B}$. The cerium spectroscopic valence $v_{\mathrm{s}}$ is defined as $v_{\mathrm{s}}=3+$ $I_{\mathrm{A}} /\left(I_{\mathrm{A}}+I_{\mathrm{B}}\right)$. The spectroscopic estimate of the f-electron count is then $n_{\mathrm{f}}=\left(4-v_{\mathrm{s}}\right)$. The spectroscopic valences are determined to be about 3.52 for bulk $\mathrm{CeO}_{2}$ and these cerium oxide nanoparticles annealed above $350{ }^{\circ} \mathrm{C}$. The corresponding f-electron count is 0.48 . Similar results for bulk $\mathrm{CeO}_{2}$ were found from the previous report. ${ }^{16,24,29}$ For the cerium oxide nanoparticles, the same spectroscopic valence and f-electron counts were obtained as compared with the bulk $\mathrm{CeO}_{2}$ case on the basis of the relative intensity (area) of the features A and B. Actually, it told us that there is indeed partial $\mathrm{CeO}_{2}$ component in the cerium oxide nanoparticles. This is consistent with the XRD results. As an example, Figure 7 shows the XANES fitting of sample Ce350. The four features and the absorption edge jump are also shown in this figure.

\section{Multielectron Excitation}

It has been well known that multielectron excitations contribute significantly to the near-edge structure in absorption spectroscopy. However, it is less well known that multielectron features $^{30-32}$ can exist at energies far above the edge. In EXAFS data analysis, the EXAFS oscillations are usually extracted assuming a smooth and monotonic background, which can be simulated by using a spline function or a polynomial. Obviously, a monotonic background cannot exclude the multielectron effect and will result in an inappropriate result in the EXAFS region 


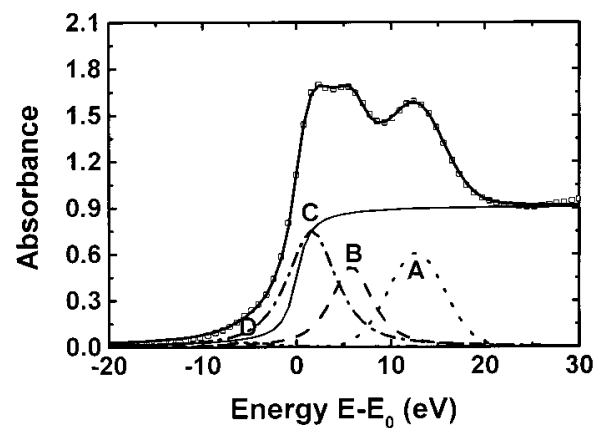

Figure 7. Fitting (solid line) of the experimental XANES spectrum (open square) of $\mathrm{Ce}-\mathrm{L}_{\mathrm{III}}$ edge for cerium oxide nanoparticles annealed at $350{ }^{\circ} \mathrm{C}$ for $2 \mathrm{~h}$ by using four resonance features $\mathrm{A}, \mathrm{B}, \mathrm{C}$, and $\mathrm{D}$ (Gaussian broadened Lorentzian functions, respectively, in dot line, dash line, dot-dash line, and dot-dot-dash line), as well as one absorption background (arctan function, fine solid lines).

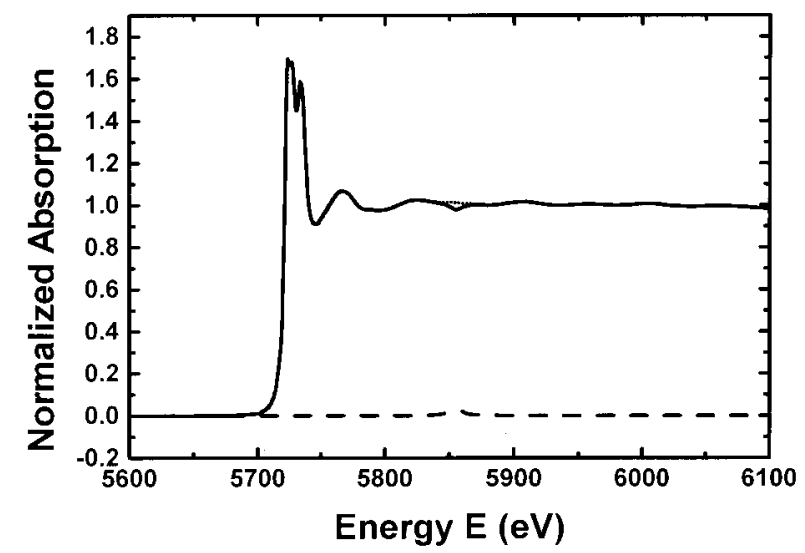

Figure 8. Multielectron excitation on the $\mathrm{Ce}-\mathrm{L}_{\mathrm{III}}$ edge of cerium oxide nanoparticles annealed at $350{ }^{\circ} \mathrm{C}$ for $2 \mathrm{~h}$. The multielectron resonance was simulated using a Lorentzian function (the lower dash line). The raw absorption curve (dot line) and the one (solid line) after subtracting the multielectron resonance are also shown in this figure.

(in the range 40 to approximately $1000 \mathrm{eV}$ ). Multielectron excitations at EXAFS region are usually inevitable in $\mathrm{Ce}^{4+}$ compounds. The theoretical calculation ${ }^{21}$ demonstrates that the main double-excitation channel is the $2 \mathrm{p} 4 \mathrm{~d} \rightarrow(5 \mathrm{~d})^{2}$ transition, while the contribution from other channels is negligible. Fonda et al. ${ }^{18}$ compared the XAFS spectra of bulk $\mathrm{CeO}_{2}$ with and without a shake-up resonance into the simulation and found that a simple EXAFS simulation is unable to provide good results. Therefore, the multielectron excitation should be subtracted before EXAFS data analysis. After normalizing the absorption curve of Ce-L $\mathrm{L}_{\mathrm{III}}$ edge to unity, the $2 \mathrm{p} 4 \mathrm{~d} \rightarrow(5 \mathrm{~d})^{2}$ transition was simulated in energy space by using a Lorentzian curve ${ }^{18}$ as follows:

$$
Y(E)=\frac{H}{1+\left(\frac{E-E_{1}}{W}\right)^{2}}
$$

where $E$ is the incident photon energy and $E_{1}$ is the position of the multielectron excitation. $H$ is the height of peak and $W$ is the half-width at half-height. For these samples annealed at 350, 500, and $700{ }^{\circ} \mathrm{C}$ and bulk $\mathrm{CeO}_{2}$, the multielectron transitions were simulated and removed in energy $5855 \mathrm{eV}$ using a Lorentzian function with width $(5.36 \mathrm{eV})$ and height $(3.4 \%$ of the absorption edge jump). For bulk $\mathrm{Ce}\left(\mathrm{NO}_{3}\right)_{3} \cdot 6 \mathrm{H}_{2} \mathrm{O}$ and nanoparticles annealed at $25{ }^{\circ} \mathrm{C}$ and $200{ }^{\circ} \mathrm{C}$, multielectron excitations are negligible and no corrections were carried out.

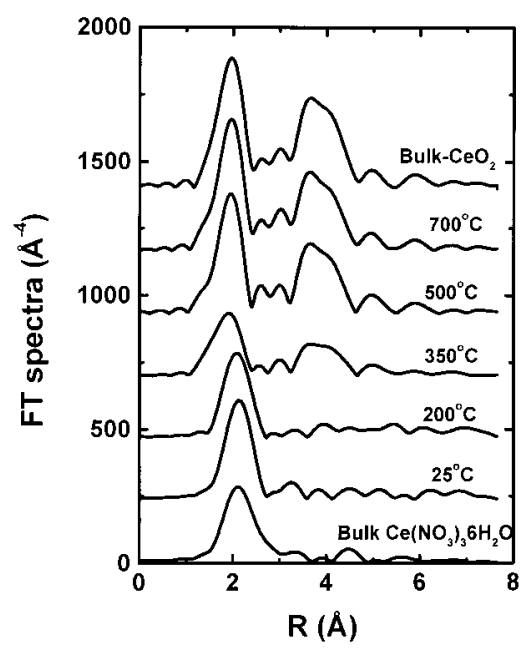

Figure 9. Fourier transform spectra of Ce- $\mathrm{L}_{\text {III }}$ absorption in bulk $\mathrm{CeO}_{2}$, CTAB-coated cerium oxide nanoparticles (annealed, respectively, at $25,200,350,500$, and $700{ }^{\circ} \mathrm{C}$ for $2 \mathrm{~h}$ ), and hydrous cerium nitrate $\left(\mathrm{Ce}\left(\mathrm{NO}_{3}\right)_{3} \cdot 6 \mathrm{H}_{2} \mathrm{O}\right)$.

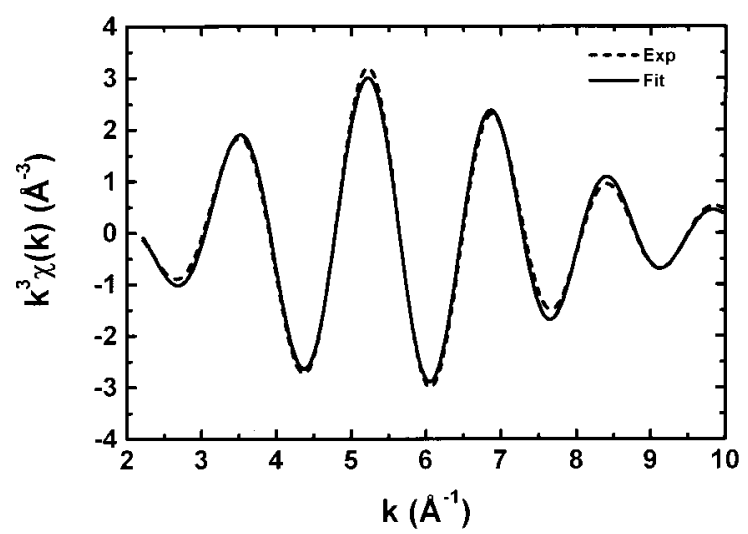

Figure 10. Experimental (dash line) and fitting (solid line) EXAFS curves with $k^{3}$-weight of $\mathrm{Ce}-\mathrm{O}$ coordination for $\mathrm{CTAB}$-coated cerium oxide nanoparticles annealed at $350{ }^{\circ} \mathrm{C}$ for $2 \mathrm{~h}$.

The simulation and removing of multielectron transitions are shown in Figure 8 for sample Ce350 as an example.

\section{EXAFS Data Analysis}

After the removing of the multielectron excitation effect, the conventional EXAFS method ${ }^{33}$ was used to extract the EXAFS signal of $\mathrm{Ce}-\mathrm{O}$ bond from the absorption curve. First, the absorption curves were transferred to $k$ space using the formula $k=\left(2 \mathrm{~m}\left(E-E_{\mathrm{o}}\right) / \hbar^{2}\right)^{1 / 2}$. The postedge absorption background was fitted and subtracted using a spline function. Then, EXAFS functions were Fourier transformed to $R$ space with $k^{3}$ weight in the range of 2.22 to $10.00 \AA^{-1}$. The region of Fourier filters was about $1.48 \AA$ A. Seven fitting parameters are allowable. Hanning windows were used in the Fourier transform and filter process. The Fourier transform spectra and the near-neighbor coordination EXAFS functions were, respectively, shown in Figures 9 and 10. The EXAFS formula ${ }^{34}$ can be expressed as follows:

$$
\chi(k)=N A(k) \int \frac{\rho(r)}{r^{2}} e^{-2 r / \lambda(r)} \sin [2 k r+\delta(k)] \mathrm{d} r
$$

Here, $A(k)$ and $\delta(k)$ are, respectively, the backscattering amplitude and phase terms. $\lambda(k)$ is the mean free path of the photoelectron. $\rho(r)$ is the partial radial probability distribution 
TABLE 2: Local Coordination Parameters around Ce in Cerium Oxide Nanoparticles Coated with Surfactants (CTAB) ${ }^{a}$

\begin{tabular}{|c|c|c|c|c|c|c|c|c|}
\hline \multirow[b]{2}{*}{ samples $^{b}$} & \multicolumn{3}{|c|}{$\mathrm{Ce}^{4+}$} & \multirow[b]{2}{*}{$\Delta \mathrm{E}_{0}(\mathrm{eV})$} & \multicolumn{4}{|c|}{$\mathrm{Ce}^{3+}$} \\
\hline & $\mathrm{N}$ & $R(\AA)$ & $\Delta \sigma^{2}\left(\AA^{2}\right)$ & & $\mathrm{N}$ & $R(\AA)$ & $\Delta \sigma^{2}\left(\AA^{2}\right)$ & $\Delta \mathrm{E}_{0}(\mathrm{eV})$ \\
\hline bulk $\mathrm{CeO}_{2}$ & 8 & 2.343 & & & & & & \\
\hline Ce700 (10 nm) & $8.0 \pm 0.3$ & $2.345 \pm 0.005$ & $0.0002 \pm 0.0010$ & $-0.5 \pm 1.0$ & & & & \\
\hline Ce500 $(6 \mathrm{~nm})$ & $7.9 \pm 0.3$ & $2.344 \pm 0.005$ & $0.0015 \pm 0.0010$ & $-0.4 \pm 1.0$ & & & & \\
\hline Ce350 (2 nm) & $8.0 \pm 0.4(81 \%)^{c}$ & 2.343 (fix) & $0.0054 \pm 0.0020$ & $0.2 \pm 1.0$ & $7.3 \pm 0.8(19 \%)^{c}$ & $2.628 \pm 0.020$ & $0.0078 \pm 0.0030$ & $3.3 \pm 2.0$ \\
\hline $\mathrm{Ce} 200(50 \mathrm{~nm})$ & $8.0 \pm 0.5(16 \%)^{c}$ & 2.343 (fix) & $\mathrm{B}=0.072 \pm 0.007$ & $0.2 \pm 1.0$ & $10.3 \pm 0.9(84 \%)^{c}$ & $2.564 \pm 0.015$ & $0.0042 \pm 0.0020$ & $3.2 \pm 2.0$ \\
\hline Ce25 (100 nm) & & & & & $10.2 \pm 0.8$ & $2.591 \pm 0.010$ & $0.0039 \pm 0.0020$ & $2.4 \pm 2.0$ \\
\hline bulk $\mathrm{Ce}\left(\mathrm{NO}_{3}\right)_{3} \cdot 6 \mathrm{H}_{2} \mathrm{O}$ & & & & & 6.0 (fix) & $2.554 \pm 0.010$ & $0.0020 \pm 0.0020$ & $3.4 \pm 2.0$ \\
\hline & & & & & 5.0 (fix) & $2.734 \pm 0.010$ & $0.0039 \pm 0.0020$ & $0.4 \pm 2.0$ \\
\hline
\end{tabular}

${ }^{a} N$ is the coordination number, $R$ is the bond length (in $\AA$ ), $\Delta \sigma^{2}$ is the Debye-Waller factor (in $\AA^{2}$ ), $B$ is the asymmetry parameter as shown in eq 3 (in $\AA$ ), and $\Delta \mathrm{E}_{0}$ is the shift of the energy threshold $(\mathrm{eV}) .{ }^{b}$ The as-prepared nanoparticles (sample Ce25 at $25{ }^{\circ} \mathrm{C}$ ) were, respectively, annealed at $200{ }^{\circ} \mathrm{C}$ (sample Ce200), $350{ }^{\circ} \mathrm{C}$ (sample Ce350), $500{ }^{\circ} \mathrm{C}$ (sample Ce500), and $700{ }^{\circ} \mathrm{C}$ (sample Ce700) for $2 \mathrm{~h} .{ }^{c}$ The content of Ce ${ }^{4+}$ or $\mathrm{Ce}^{3+}$ components in sample $\mathrm{Ce} 200$ and $\mathrm{Ce} 300$.

of atoms in this shell (centered around its mean value, $R$ ). $N$ neighbors stand at average distance $R$ far away from the absorber.

For no or little radially distorted system, a symmetrical shape for $\rho(r)$ can be used, such as a Gaussian probability distribution. The EXAFS formula in eq 2 can be written as the common form. However, for moderate and large disordered system (of static or thermal origins), a symmetrical distribution function is not enough to describe the structure. In this case, an asymmetrical distribution is necessary, for example, weighted exponential distribution ${ }^{34,35}$ in the case of $m=1$ as listed in eq 3 .

$$
\rho(r)=\frac{r-R+2 B}{B^{2}} \exp \left[-\frac{r-R+2 B}{B}\right]
$$

$B$ is an asymmetry parameter (in $\AA$ ). The average bond length $R$ can be written as $R=A+2 B$. $A$ is the low limit of the bond-length distribution function.

In our EXAFS data analysis, bulk $\mathrm{CeO}_{2}$ was chosen as the reference sample. The backscattering amplitude $A_{\mathrm{s}}(\pi, k)$ and phase shift $\delta_{\mathrm{s}}(\pi, k)$ of $\mathrm{Ce}-\mathrm{O}$ bond were extracted from the reference spectrum of $\mathrm{Ce}-\mathrm{L}_{\text {III }}$ edge of bulk $\mathrm{CeO}_{2}$ with the structural parameters ${ }^{36} N=8$ and $R=2.343 \AA$. Because of the transferability of the backscattering amplitude and phase shift, they were substituted for those of the unknown samples in eq 2. A single-shell symmetrical distribution was tested first in all samples. The three samples Ce25, Ce500, and Ce700 can be well fitted. For sample Ce200, a single-shell distribution or double shells with symmetrical distribution cannot get reasonable fitting and results. Therefore, a symmetrical distribution was used to describe the dominant $\mathrm{Ce}^{3+}$ component, and an asymmetrical distribution as shown in eq 3 was used to describe the possible $\mathrm{Ce}^{4+}$ component. For sample $\mathrm{Ce} 350$ and bulk $\mathrm{Ce}$ $\left(\mathrm{NO}_{3}\right)_{3} \cdot 6 \mathrm{H}_{2} \mathrm{O}$, a single shell with either symmetrical or asymmetrical distributions cannot get a reasonable fitting. A doubleshell fitting had to be used in the two samples. Table 2 tabulated all fitting parameters. The fitting curve for experimental EXAFS function was shown in Figure 10 for sample Ce350.

\section{Results and Discussion}

From XANES results, we know that the as-prepared cerium oxides nanoparticles (sample Ce25) and those annealed at 200 ${ }^{\circ} \mathrm{C}$ (sample $\mathrm{Ce} 200$ ) are mainly characteristic of $\mathrm{Ce}^{3+}$. The nanoparticles annealed at $500{ }^{\circ} \mathrm{C}$ (sample Ce500) and $700{ }^{\circ} \mathrm{C}$ (sample Ce700) are almost the same with bulk $\mathrm{CeO}_{2}$ and show $\mathrm{Ce}^{4+}$ characteristic. The nanoparticles annealed at $350{ }^{\circ} \mathrm{C}$ (sample Ce350) have both $\mathrm{Ce}^{3+}$ and $\mathrm{Ce}^{4+}$ characteristic. This implies evidently that there is a chemical transformation from
$\mathrm{Ce}^{3+}$ component to $\mathrm{Ce}^{4+}$ component as the sample was annealed around $350{ }^{\circ} \mathrm{C}$. This conclusion has been confirmed by our EXAFS results.

In sample preparation, we know that one of the starting substances is the bulk $\mathrm{Ce}\left(\mathrm{NO}_{3}\right)_{3} \cdot 6 \mathrm{H}_{2} \mathrm{O}$, in which Ce has the $\mathrm{Ce}^{3+}$ oxidation state. According to the crystal structure, ${ }^{37}$ there are 11 oxygens surrounding Ce with 11 different bond lengths (average bond length $2.6376 \AA$ ). These $\mathrm{Ce}-\mathrm{O}$ bonds can be separated into two average shells, that is, six oxygen atoms at $2.554 \AA$ and five oxygen atoms at $2.7338 \AA$. In our EXAFS analysis, we had to use two shells to fit the EXAFS spectrum of bulk $\mathrm{Ce}\left(\mathrm{NO}_{3}\right)_{3} \cdot 6 \mathrm{H}_{2} \mathrm{O}$. The coordination numbers were, respectively, fixed at 6 and 5 . We got the following two shells: six oxygen atoms located at $2.55 \AA$ and five oxygen atoms located at $2.73 \AA$. These structural parameters are in excellent agreement with the crystal structure ${ }^{37}$ of $\mathrm{Ce}\left(\mathrm{NO}_{3}\right)_{3} \cdot 6 \mathrm{H}_{2} \mathrm{O}$. Simultaneously, it also demonstrates that the EXAFS analysis is reasonable.

Sample Ce25 has a similar spectral feature as bulk $\mathrm{Ce}\left(\mathrm{NO}_{3}\right)_{3}$. $6 \mathrm{H}_{2} \mathrm{O}$ with the same oxidation state of $\mathrm{Ce}^{3+}$. However, their atomic structures are different. There are about 10 oxygen atoms around central Ce with an average bond length about $2.591 \AA$. The coordination number and average bond length slightly decrease in sample $\mathrm{Ce} 25$ than in bulk $\mathrm{Ce}\left(\mathrm{NO}_{3}\right)_{3} \cdot 6 \mathrm{H}_{2} \mathrm{O}$. In the former, one single shell is sufficient to describe the local atomic structures. In the latter, two shells were used, although the change of nominal Debye-Waller factors are not so large for the single shell of $\mathrm{Ce} 25$ and the two shells of $\mathrm{Ce}\left(\mathrm{NO}_{3}\right)_{3} \cdot 6 \mathrm{H}_{2} \mathrm{O}$. Actually, the local atomic structure is more ordered in sample $\mathrm{Ce} 25$ than in bulk $\mathrm{Ce}\left(\mathrm{NO}_{3}\right)_{3} \cdot 6 \mathrm{H}_{2} \mathrm{O}$. This agrees with the XANES features of the two samples where $\mathrm{Ce} 25$ has higher intensity and narrower width in the main peak than bulk $\mathrm{Ce}\left(\mathrm{NO}_{3}\right)_{3} \cdot 6 \mathrm{H}_{2} \mathrm{O}$.

With the increase of annealing temperature, the atomic structures will change. Especially, the surfactant CTAB will be decomposed. When the annealing temperature was $200{ }^{\circ} \mathrm{C}$, a single shell could not fit the EXAFS spectrum well. We think that some tiny nuclei with $\mathrm{Ce}^{4+}$ oxidation state had been formed as indicated by a faint feature $A$ appearing on the XANES spectrum. At the same time, the atomic structures of $\mathrm{Ce}^{3+}$ matrix should be changed with the increase of annealing temperature and surfactant decomposition. A double-shell fitting has to be used. Unfortunately, two symmetrical distribution functions are not possible to get a reasonable result for the sample Ce200. This means that the atomic structures are possibly divergent from the symmetrical distribution because of the larger disorder and distortion originated from the chemical transformation. We used a symmetrical distribution function to describe the $\mathrm{Ce}^{3+}$ matrix. An asymmetrical distribution function shown as eq 3 was used to describe the new component that just appeared in 
the sample Ce200. To decrease the number of fitting parameters, the average bond length $R$ of the new component was fixed at $2.343 \AA$ in the fitting procedure. We guess that the new component has a similar structure as bulk $\mathrm{CeO}_{2}$ with eight oxygen atoms surrounding a central $\mathrm{Ce}$ atom. This is clearer from the XANES spectral features of sample Ce350. From the nominal coordination number, the content of the new component was calculated to be about $16 \%$. The remainder was the component of $\mathrm{Ce}^{3+}$, and its real coordination number was determined to be about 10 . Cerium atom has about 10 oxygen neighbors located at $2.56 \AA$ in the $\mathrm{Ce}^{3+}$ matrix. The new component, which has the similar structural parameters as bulk $\mathrm{CeO}_{2}$, is quite disordered and presents an asymmetrical distribution.

Sample Ce350 obviously is a mixture of two components (i.e., the $\mathrm{Ce}^{4+}$ and $\mathrm{Ce}^{3+}$ components). A quite persuasive XANES spectrum for this chemical transformation is shown in Figure 5. The $\mathrm{Ce}^{4+}$ characteristic is dominant and is quite evident and is similar to bulk $\mathrm{CeO}_{2}$. A double-shell symmetrical distribution was used to describe the local atomic structures of sample Ce350. One shell was used to describe the $\mathrm{Ce}^{3+}$ component. Another shell was used to describe the $\mathrm{Ce}^{4+}$ component. The $\mathrm{Ce}^{4+}$ component in $\mathrm{Ce} 350$ was assumed to have the similar structures as bulk $\mathrm{CeO}_{2}$, and its bond length was fixed at $2.343 \AA$ in the fitting procedure. A reasonable fitting result was obtained. In the same way as in sample Ce200, we evaluated the contents of the two components. They are, respectively, $81 \%\left(\mathrm{Ce}^{4+}\right.$ component $)$ and $19 \%\left(\mathrm{Ce}^{3+}\right.$ component). There are about seven oxygen atoms surrounding a central $\mathrm{Ce}$ atom with bond length of $2.63 \AA$ for the $\mathrm{Ce}^{3+}$ component. The contents of the two components are in excellent agreement with the XANES results.

From Table 2, we know that the structural parameters of samples $\mathrm{Ce} 500$ and $\mathrm{Ce} 700$ are almost the same with bulk $\mathrm{CeO}_{2}$ except the slightly different Debye-Waller factors. Although sample Ce700 was annealed at a higher temperature than sample Ce500, the Debye-Waller factor is bigger in the latter than in the former. The XAFS data were collected at room temperature. Therefore, we can roughly consider that all samples have the same thermal disorder. The bigger Debye-Waller factor in Ce500 than in Ce700 can be attributed to the origin of the static structure disorder. Sample Ce500 has almost been transferred into $\mathrm{Ce}^{4+}$ component. Probably some distortions and defects originating from the chemical transformation still existed. Because the structural relaxation is easier and faster at a higher temperature, these distortion and defects due to the chemical transformation procedure were mostly relaxed, and the crystalline structures tend to be more perfect and closer to the bulk $\mathrm{CeO}_{2}$ in sample Ce700 than in sample Ce500.

The nanoparticles annealed at $350{ }^{\circ} \mathrm{C}$ have the biggest Debye-Waller factors as we expected. Obviously, the coexisting of two components will cause larger distortions and defects in the sample. Especially at the interface between the two components, a lattice mismatch is inevitable. This will result in the increasing of Debye-Waller factors. In the cases of annealing temperature below $350{ }^{\circ} \mathrm{C}$, those samples probably contain some structural waters or other ligands. In the annealing procedure, the surfactant was gradually decomposed. The structural waters or other ligands in the nanoparticles were gradually removed. The higher the annealing temperature, the faster the change. However, the temperature is not high enough and the heating time is not long enough to remove all the surfactants and to relax all the distortion and defects at temperature below $350^{\circ} \mathrm{C}$. Therefore, the static disorder tends to increase with increase of the annealing temperature. When the sample was annealed above $350{ }^{\circ} \mathrm{C}$, the surfactant CATB was decomposed mostly or completely. The structural water or other ligands were removed and the chemical transformation was completed, only a near-pure new component was left. Some distortion and defects were kept in the sample. The higher the annealing temperature, the faster and easier the distortion and defect relaxed. So the local atomic structures should become more ordered. The Debye-Waller factors present a decreasing tendency with increase of the annealing temperature above 350 ${ }^{\circ} \mathrm{C}$.

The X-ray diffraction pattern of sample Ce25 is very similar to that of surfactant CTAB. This demonstrates that the surfactant CTAB is almost perfect in the sample Ce25. Except for the diffraction peaks from the surfactant $\mathrm{CTAB}$, no other diffraction peaks could be found. We believe that surfactant CTAB was the dominant component in this sample. These nanoparticles were in amorphous state and contained some structural waters or other ligands. After the sample was annealed at $200{ }^{\circ} \mathrm{C}$, its $\mathrm{X}$-ray diffraction pattern differed from that of the pure surfactant $\mathrm{CTAB}$, without any diffraction peak coming from the cerium oxide nanoparticles again. These nanoparticles still kept amorphous form as confirmed by electron diffraction pattern shown in the inset of Figure 1. These differences in the X-ray diffraction pattern demonstrate that surfactant $\mathrm{CTAB}$ was partially decomposed. Nevertheless, the annealing at $200{ }^{\circ} \mathrm{C}$ did not remove all surfactants coated on the cerium oxide nanoparticles. As the annealing temperature increased to 350 ${ }^{\circ} \mathrm{C}$, the diffraction peaks coming from the surfactant CTAB did not disappear at all. Surfactants probably left few ligands contacted with the nanoparticles. At the same time, the contribution from the cerium oxide nanoparticles started appearing. Although the surfactants were not completely removed, a quite broadened peak around $29^{\circ}$ indicated the formation of crystalline $\mathrm{CeO}_{2}$. Because the average particle size is quite small $(\sim 2 \mathrm{~nm})$, the diffraction peaks from $\mathrm{CeO}_{2}$ component are very weak and broadened. Certainly, the structural waters or hydrates and other ligands in the nanoparticles were gradually evaporated or removed upon heating resulting in a separation of the nanoparticles and in the decreasing of particle size. Few $\mathrm{Ce}^{3+}$ components were left in amorphous and surface forms. A more detailed comparison will be given later between the structures of known compounds and the structural parameters of these nanoparticles. After the samples were annealed above $500{ }^{\circ} \mathrm{C}$, surfactants $\mathrm{CTAB}$ were completely removed from the nanoparticles. Only crystalline and $\mathrm{CaF}_{2}$ type cerium oxide nanoparticles remained.

Combining these XANES, EXAFS, and XRD results, it is unambiguous that a chemical transformation occurs as the samples were annealed around $300{ }^{\circ} \mathrm{C}$. That is to say, these cerium oxide nanoparticles with $\mathrm{Ce}^{3+}$ form were transferred into $\mathrm{Ce}^{4+}$ component. This chemical transformation was roughly evaluated to start at $200{ }^{\circ} \mathrm{C}$ and end at $400{ }^{\circ} \mathrm{C}$. The mechanism of this chemical transformation is discussed as follows.

First, surfactants formed "microreactors" with a certain size $(\sim 100 \mathrm{~nm})$ in the organic solution. Cerium oxide nanoparticles with some structural waters and other ligands were formed in these microreactors. Their sizes were limited to the size of the microreactors. After the rotatory evaporation of the colloid solutions, the cerium oxide nanoparticles contained some structural water and were in an amorphous form with $\mathrm{Ce}^{3+}$ oxidation state. The surplus of surfactant was also left in the sample. Second, as the annealing temperature increased to 200 ${ }^{\circ} \mathrm{C}$, some surfactants were decomposed but still left the ligands 
coated on the nanoparticles. On the other hand, $\mathrm{Ce}^{4+}$ component began to nucleate in the $\mathrm{Ce}^{3+}$ matrix because of the loss of some structural waters and ligands. The surfactant decomposing and the removing of structural water decreased the nominal particle size. Third, at annealing at $350{ }^{\circ} \mathrm{C}$, the surfactants were almost removed and only few surfactant ligands were left on the surface of the nanoparticles. The cerium oxides lost most of the structural waters and other ligands. Lots of tiny $\mathrm{Ce}^{4+}$ nuclei were blooming at the previous $\mathrm{Ce}^{3+}$ matrix. The nanoparticles were split by the removing of structural waters and almost reached the minimum of the particle size. $\mathrm{Ce}^{3+}$ component was mostly transferred into $\mathrm{CeO}_{2}$. Some distortions and defects were generated at the interface of components. From $\mathrm{Ce} 200$ to $\mathrm{Ce} 350$, it is $\mathrm{Ce}^{4+}$ instead of $\mathrm{Ce}^{3+}$ that is becoming the dominant component, and the change from amorphous to crystalline forms results in the abrupt change from Ce200 to Ce350 as revealed by XRD, XAFS, and the corresponding changes in particle size. Finally, as the annealing temperature reached $500{ }^{\circ} \mathrm{C}$ and above, the surfactants, possible structural waters, and other ligands were completely removed. The $\mathrm{Ce}^{3+}$ matrix completely disappeared. The nuclei of $\mathrm{Ce}^{4+}$ component $\left(\mathrm{CeO}_{2}\right)$ were grown up. The crystalline structures of $\mathrm{CeO}_{2}$ became gradually perfect with the relaxation of distortions and defects. As the annealing temperature reached higher than 700 ${ }^{\circ} \mathrm{C}$, the average particle size exceeded $10 \mathrm{~nm}$. No obvious structure differences from the bulk $\mathrm{CeO}_{2}$ could be probed by using EXAFS technique. Evidently, it was the removal of the structural waters or other ligands that drove the chemical transformation.

In the two samples Ce200 and Ce350, we suppose that the nanoparticles consist of two parts, that is, the $\mathrm{Ce}^{3+}$ component and the $\mathrm{Ce}^{4+}$ component $\left(\mathrm{CeO}_{2}\right)$. Some reports about the coexistence of $\mathrm{Ce}^{3+}$ and $\mathrm{Ce}^{4+}$ components have been found. For example, sintering of nanosize $\mathrm{CeO}_{2}$ powders ${ }^{38,39}$ will lead that $\mathrm{CeO}_{2}$ was reduced to $\mathrm{Ce}_{2} \mathrm{O}_{3}$ and oxygen gas was released. Dopants with a valence lower than +4 in $\mathrm{CeO}_{2}{ }^{40}$ or argon sputtering and hydrogen exposure to the $\mathrm{CeO}_{2}{ }^{41}$ will introduce $\mathrm{Ce}^{3+}$ related defects on the surface of $\mathrm{CeO}_{2}$ and will lead to the capping of oxygen vacancies at the surface or high concentration of $\mathrm{Ce}^{3+}$ at surface and subsurface sites. Computer modeling ${ }^{42}$ for the $\mathrm{CeO}_{2}$ surface with anion vacancy centers predicted that for the (111) surface, actually, generation of vacancies does not seem more favorable than full reduction of (part of) the $\mathrm{CeO}_{2}$ phase to $\mathrm{Ce}_{2} \mathrm{O}_{3}$. All these reports demonstrate that a $\mathrm{Ce}^{3+}$ component probably exists on the surface of $\mathrm{CeO}_{2}$ particles. In this paper, we report a chemical transformation from $\mathrm{Ce}^{3+}$ component to $\mathrm{CeO}_{2}$. We believe that it is the removal of structural water or other ligands in $\mathrm{Ce}^{3+}$ matrix that drives this chemical transformation. On the basis of the previous reports, we think that the $\mathrm{Ce}^{3+}$ component was coated on the surface of the $\mathrm{Ce}^{4+}$ component. Therefore, the nanoparticles formed approximately a core-shell structure. The $\mathrm{Ce}^{4+}$ component is the core part, while the $\mathrm{Ce}^{3+}$ component is the shell (or surface) part. The nanoparticles were coated by surfactants CTAB or their ligands.

As shown in Table 2, all $\mathrm{Ce}^{4+}$ components have the same $\mathrm{Ce}-\mathrm{O}$ coordination number ( 8 ) and bond length (2.34 $\mathrm{A})$, only this part has obvious diffraction peaks as shown in Figure 3. The $\mathrm{Ce}^{3+}$ components are different from different samples. They may have different coordination numbers and bond lengths. For sample $\mathrm{Ce} 25$, there is only a $\mathrm{Ce}^{3+}$ component with about 10 oxygen atoms surrounding a $\mathrm{Ce}$ atom. The average $\mathrm{Ce}-\mathrm{O}$ bond length is $2.59 \AA$. It is closer to the average structures ${ }^{43}$ of Ce$\left(\mathrm{NO}_{3}\right)_{3} \cdot 4 \mathrm{H}_{2} \mathrm{O}$ where 10 oxygen atoms surround a $\mathrm{Ce}$ atom with an average $\mathrm{Ce}-\mathrm{O}$ bond length of $2.5823 \AA$. For sample $\mathrm{Ce} 200$, there are about $16 \%$ of $\mathrm{Ce}^{4+}$ component and $84 \%$ of $\mathrm{Ce}^{3+}$ component. The $\mathrm{Ce}^{3+}$ component presents about 10 oxygen atoms with an average $\mathrm{Ce}-\mathrm{O}$ bond length of $2.56 \AA$. This structure is closer to the average structures ${ }^{44}$ of $\mathrm{Ce}(\mathrm{OH})_{3}$ in which nine oxygen atoms surround $\mathrm{Ce}$ with an average $\mathrm{Ce}-\mathrm{O}$ bond length of $2.5543 \AA$. These comparisons support our assumption that some structural waters and other ligands were contained in the samples Ce25 and Ce200. For sample Ce350, there are about $81 \%$ of $\mathrm{Ce}^{4+}$ component and $19 \%$ of $\mathrm{Ce}^{3+}$ component. This $\mathrm{Ce}^{3+}$ component is different from both formers. There are about seven oxygen atoms located at $2.63 \AA$. Except the coordination number decreases, the bond length increases. We did not find a known and closer crystalline structure of cerium oxides. There are seven oxygen atoms surrounding Ce with average $\mathrm{Ce}-\mathrm{O}$ bond length of $2.5047 \AA$ for crystalline $\mathrm{Ce}_{2} \mathrm{O}_{3},{ }^{45}$ but the $\mathrm{Ce}-\mathrm{O}$ bond length $(2.63 \AA)$ of the $\mathrm{Ce}^{3+}$ component in sample $\mathrm{Ce} 350$ is much larger than that in crystalline $\mathrm{Ce}_{2} \mathrm{O}_{3}$. Probably, the particle size is too small in this sample. Most atoms locate at the surface of the nanoparticles. Some surface atoms have bonded with the survival ligands of surfactants that leads the elongation of the $\mathrm{Ce}-\mathrm{O}$ bond length.

The EXAFS result is consistent with the XANES result. In the latter, the $\mathrm{Ce}^{3+}$ and $\mathrm{Ce}^{4+}$ features were found simultaneously in the XANES spectrum of sample Ce350. The multielectron excitation has serious influence on the EXAFS spectra of Ce$\mathrm{L}_{\text {III }}$ of $\mathrm{Ce}^{4+}$ compounds. It is necessary to subtract the multielectron excitation effect before a reasonable EXAFS data analysis can be obtained. Although all $\mathrm{Ce}^{4+}$ components have the same crystalline structure (coordination numbers and bond lengths) as bulk $\mathrm{CeO}_{2}$ except for the different disorder or atompair distribution function, the $\mathrm{Ce}^{3+}$ component in amorphous form is not stable with the temperature increasing. Its coordination number and bond length change with the increase of annealing temperatures. The as-prepared product is of $\mathrm{Ce}^{3+}$ oxidation state. $\mathrm{CeO}_{2}$ type cerium-oxide nanoparticles can be obtained by heating the sample in air condition. Surfactant CTAB shows effects on the atomic structures of nanoparticles, especially with a large surface-to-volume ratio. Although the surfactant was partially decomposed in the annealing procedure, there are still some ligands (or heads) surviving at the surface of nanoparticles until $350{ }^{\circ} \mathrm{C}$. Structures and chemical transformation of these cerium oxide nanoparticles were identified by X-ray absorption studies. This study describes the synthesis of cerium oxide nanoparticles coated by surfactant CTAB and provides the information of their structures and chemical transformation. It is important for the further application of these nanoparticles.

\section{Conclusion}

Cerium oxide nanoparticles coated with surfactant CTAB were prepared. These nanoparticles were annealed, respectively, at $25,200,350,500$, and $700{ }^{\circ} \mathrm{C}$ for $2 \mathrm{~h}$. The particle sizes were characterized to be $100,50,2,6$, and $10 \mathrm{~nm}$ by using high-resolution TEM and XRD. X-ray absorption spectra were used to probe the structures. A chemical transformation from $\mathrm{Ce}^{3+}$ to $\mathrm{Ce}^{4+}$ components was found in about the temperature range of $200-400{ }^{\circ} \mathrm{C}$. After the annealing was performed at $500{ }^{\circ} \mathrm{C}$ and $700{ }^{\circ} \mathrm{C}$, a single phase with $\mathrm{Ce}^{4+}$ oxidation state and $\mathrm{CaF}_{2}$ type structures was obtained. They have the same crystalline structures with bulk $\mathrm{CeO}_{2}$ except for the different Debye-Waller factors. The room-temperature products are in amorphous state and present $\mathrm{Ce}^{3+}$ characteristics. The samples annealed at $200{ }^{\circ} \mathrm{C}$ and $350{ }^{\circ} \mathrm{C}$ are, respectively, a mixture of 
amorphous $\mathrm{Ce}^{3+}$ component and crystalline $\mathrm{Ce}^{4+}$ component. These nanoparticles consist of two parts, that is, the core part $\left(\mathrm{Ce}^{4+}\right)$ and the surface part $\left(\mathrm{Ce}^{3+}\right)$. The surface parts change with the increase of annealing temperature. The core parts are always the same with bulk $\mathrm{CeO}_{2}$. The contents of the core parts for sample $\mathrm{Ce} 200$ and $\mathrm{Ce} 350$ are, respectively, about $16 \%$ and $81 \%$. The corresponding contents of shell parts are, respectively, $84 \%$ and $19 \%$. Multiple electron excitations at EXAFS region must be removed before a reasonable EXAFS data analysis can be obtained.

Acknowledgment. Wu Zhonghua is grateful to the Royal Society KC WONG Fellowship and is indebted to the financial support by the foundation for returned scholar of Chinese Academy of Science and Chinese Ministry of Education.

\section{References and Notes}

(1) Ying, J. Y. Mater. Lett. 1992, 15, 180

(2) Kubo, R. J. Phys. Soc. Jpn. 1962, 17 (5), 986.

(3) Zhou, Y. C.; Rahaman, M. N. J. Mater. Res. 1993, 8, 1680.

(4) Hirano, M.; Kato, E. J. Am. Ceram. Soc. 1996, 79, 777.

(5) Chebgyun, W.; Yitai, Q.; Changsui, W.; Li, Y.; Guiwen, Z. Mater. Sci. Eng., B 1996, 39, 160 .

(6) Hirano, M.; Kato, E. J. Mater. Sci. Lett. 1996, 15, 1249.

(7) Mitsuru, H.; Yoshikiro, K.; Masahiro, K.; Yasuhiko, S. J. Mater. Sci. Lett. 1996, 15, 1608

(8) Tschoipe, A.; Ying, J. Y. Nanostruct. Mater. 1994, 4, 617.

(9) Guillou, N.; Nistor, L. C.; Fuess, H.; Hahn, H. Nanostuct. Mater. $1997,8,545$.

(10) Vallet-Regi, M.; Conde, F.; Ragel, S. V. Mater. Sci. Forum 1997, 235-238, 291.

(11) Toshiyuki, M.; Kazuyasu, F.; Ken-ichi, M.; Gin-ya, A.; Takao, S.; Hirotari, M. Chem. Mater. 1997, 9, 2197.

(12) Brust, M.; Walker, M.; Bethel, D.; Schiffrin, D. J.; Whyman, R. J. Chem. Soc., Chem. Commun. 1994, 801.

(13) Beaurepaire, E.; Kappler, J. P.; Malterre, D.; Krill, G. Europhys. Lett. 1988, 5, 369.

(14) Bianconi, A.; Marceli, A.; Dexpert, H.; Karnatak, R.; Kotani, A.; Jo, T.; Petiau, J. Phys. Rev. B 1987, 35, 806-812. Soldatov, A. V.; Ivanchenko, T. S.; Kotani, A.; Bianconi, A. Physica B 1995, 208-209, 53.

(15) Malterre, D. Phys. Rev. B 1991, 43, 1391.

(16) Soldatov, A. V.; Ivanchenko, T. S.; Della Longa, S.; Kotani, A.; Iwamoto, Y.; Bianconi, Y. Phys. Rev. B 1994, 50, 5074

(17) Kodre, A.; Arcon, A.; Hribar, M.; Stuhec, M.; Villain, F.; Drube, W.; Tröger, L. Physica B 1995, 208-209, 379.
(18) Fonda, E.; Andreatta, D.; Colavita, P. E.; Vlaic, G. J. Synchrotron Radiat. 1999, 6, 34

(19) Li, G.; Bridges, F.; Brown, G. Phys. Rev. Lett. 1992, 68, 1609

(20) Mukoyama, T.; Ito, Y. Nucl. Instrum. Methods Phys. Res., Sect. B 1994, 87,26

(21) Chaboy, J.; Marcelli, A.; Tyson, T. A. Phys. Rev. B 1994, 49, 11652.

(22) Nachimuthu, P.; Shih, W. C.; Liu, R. S.; Jang, L. Y.; Chen, J. M. J. Solid State Chem. 2000, 149, 408.

(23) Weller, M. T. Inorganic Materials Chemistry; Oxford University Press: New York, 1994; p 25.

(24) Dexpert, H.; Karnatak, R. C.; Esteva, J. M.; Connerade, J. P.; Gasgnier, M.; Caro, P. E.; Albert, L. Phys. Rev. B 1987, 36, 1750.

(25) Boikov, Y. A.; Claeson, T.; Erts, D.; Bridges, F.; Kvitky, Z. Phys. Rev. B 1997, 56, 11312.

(26) Bazin, D. C.; Sayers, D. A.; Rehr, J. J. J. Phys. Chem. B 1997, 101,11040 .

(27) Capehart, T. W.; Mishra, R. K.; Fuerst, C. D.; Meisner, G. P.; Pinkerton, F. E.; Herbst, J. F. Phys. Rev. B 1997, 55, 11496.

(28) Vandormael, D.; Grandjean, F.; Briois, V.; Middleton, d. P.; Buschow, K. H. J.; Long, C. J. Phys. Rev. B 1997, 56, 6100.

(29) Paparazzo, E.; Ingo, G. M.; Zacchetti, N. J. Vac. Sci. Technol., A 1991, 9, 1416.

(30) Benfield, R. E.; Filipponi, A.; Bowron, D. T.; Newport, R. J.; Gurman, S. J. J. Phys.: Condens. Matter 1994, 6, 8429.

(31) D'Angelo, P.; Di Cicco, A.; Filipponi, A.; Pavel, N. V. Phys. Rev. A 1993, 47, 2055 .

(32) Filipponi, A.; Tyson, T. A.; Hodgson, K. O.; Mobilio, S. Phys. Rev. A 1993, 48, 1328.

(33) Lytle, F. W.; Sayers, D. E.; Stern, E. A. Physica B 1989, 158, 701.

(34) Sayers, D. E.; Bunker, B. A. In X-ray Absorption: Principle, Applications and Techniques of EXAFS, SEXAFS and XANES; Koningsberger, D. C., Prins, R., Eds.; Wiley: New York, 1988; Chapter 9.

(35) Wu, Z. H.; Farges, F. Physica B 1999, 266, 282.

(36) Whitfield, H. J.; Roman, D.; Palmer, A. R. J. Inorg. Nucl. Chem. 1966, 28, 2817.

(37) Milinski, N.; Ribar, B.; Sataric, M. Cryst. Struct. Commun. 1980 , $9,473$.

(38) Zhou, Y. C.; Mohamed, N. R. Acta Mater.1997, 45, 3635.

(39) Tschopea, A.; Birringera, R. Nanastruct. Mater. 1997, 9, 591.

(40) Palmqvist, A. e. C.; Wirde, M.; Gelius, U.; Muhammed, M. Nanastruct. Mater. 1999, 11, 995.

(41) Pfau, A.; Schierbaum, K. D. Surf. Sci. 1994, 321, 71.

(42) Conesa, J. C. Surf. Sci. 1995, 339, 337.

(43) Milinski, N.; Radivojevic, P.; Ribar, B.; Djuric, S. Cryst. Struct. Commun. 1982, 11, 1241.

(44) Mullica, D. F.; Oliver, J. D.; Milligan, W. O. Acta Crystallogr., Sect. $B$ 1979, 35, 2668.

(45) Baernighausen, H.; Schiller, G. J. Less-Common Met. 1985, 110, 